\title{
Characterisation of Intermetallic Phases in Fusion Welded Commercially Pure Titanium and Stainless Steel 304
}

\author{
Timotius Pasang ${ }^{1, *}$, Stevin Snellius Pramana ${ }^{2}{ }^{\mathbb{D}}$, Michael Kracum ${ }^{3}$, \\ Wojciech Zbigniew Misiolek ${ }^{3}{ }^{\circledR}$, Mona Aziziderouei ${ }^{1}$, Masami Mizutani ${ }^{4}$ and Osamu Kamiya ${ }^{5}$ \\ 1 School of Engineering, Computer and Mathematical Sciences, Auckland University of Technology, \\ Auckland 1020, New Zealand; mana.azizi@hotmail.com \\ 2 School of Engineering, Newcastle University, Newcastle upon Tyne NE1 7RU, UK; \\ Stevin.Pramana@newcastle.ac.uk \\ 3 Loewy Institute \& Department of Materials Science and Engineering, Lehigh University, \\ 5 East Packer Avenue, Bethlehem, PA 18015, USA; mkracum411@gmail.com (M.K.); \\ wzm2@lehigh.edu (W.Z.M.) \\ 4 Joining and Welding Research Institute (JWRI), Osaka University, Osaka 567-0047, Japan; \\ mizutani@jwri.osaka-u.ac.jp \\ 5 Faculty of Engineering Science, Department of System Design Engineering, Akita University, \\ 1-1 Tegatagakuen-machi, Akita 010-8502, Japan; kamiya@gipc.akita-u.ac.jp \\ * Correspondence: tpasang@aut.ac.nz
}

Received: 3 October 2018; Accepted: 19 October 2018; Published: 24 October 2018

\begin{abstract}
A series of trials to fusion weld commercially pure titanium (CPTi) to stainless steel 304 (SS304) have been conducted using laser beam welding (LBW) and gas tungsten arc welding (GTAW). Neither technique produced adequate weld joints with LBW showing a more promising result, while GTAW yielded separation of the workpieces immediately after welding. Cracking and fracturing took place mainly on the SS304 side, which was explained by the differences in the materials' thermal properties. Various intermetallic phases formed during welding that were identified using energy dispersive X-ray spectroscopy (EDS) and electron backscattered diffraction (EBSD) technique and were compared with an isothermal ternary phase diagram of Fe-Cr-Ti. Their corresponding hardness values are reported and correlated with alloy compositions.
\end{abstract}

Keywords: laser beam welding; gas tungsten arc welding; commercially pure titanium; stainless steel 304; phase diagram; hardness

\section{Introduction}

Dissimilar welding is increasingly popular in industrial applications for various reasons, such as weight reductions, functionalities, design compatibilities and cost reductions. Various manufacturing companies have taken advantage of dissimilar joints in automotive, aerospace, nuclear, smelter, construction, petrochemical, medical and micro-electronics industries. Challenges are the mismatch in mechanical properties, melting temperatures, crystal structures, solubility and, perhaps more importantly, the thermal properties such as thermal conductivity, thermal expansion and thermal diffusivity.

It is known that fusion welding of titanium to stainless steel is very challenging without an interlayer [1]. This is often mitigated by incorporating brittle intermetallic compounds in the softer matrix phase [2,3]. Various attempts have been made in the past to join titanium and stainless steel. Most of the studies, however, have focused on the joint between Ti6Al4V and the stainless steel, 
e.g., SS304 or SS316. Some of the common methods to join dissimilar metals are (i) fusion welding, including electron beam and laser beam welding, and (ii) solid-state welding, such as diffusion bonding, explosive welding, friction welding and, more recently, friction stir welding. They are summarised as the following.

Direct studies of CPTi and stainless steel welds were performed by Shanmugarajan and Padmanabham on autogenous (no filler added) welds as well as with interlayers such as vanadium (V) and tantalum (Ta) using a $\mathrm{CO}_{2}$ laser welding technique [4]. While the autogenous welds resulted in immediate fracture after welding, regardless of welding speed and beam position, the welds with interlayers did not show a significant strength improvement with a maximum of $44 \mathrm{MPa}$ ultimate tensile strength (UTS) and a small degree of ductility obtained with Ta as an interlayer. Various phases were observed on the fracture surface including $\mathrm{Fe}_{0.2} \mathrm{Ni}_{4.8} \mathrm{Ti}_{5}$ (on both the CPTi and stainless steel sides), $\mathrm{NiTi}$ (on the Ti side) and $\mathrm{Cr}_{2} \mathrm{Ti}$ (on the stainless-steel side). The authors claimed that the thickness of the intermetallic layer was more than $10 \mu \mathrm{m}$ thick at the location of the fracture; hence, it fractured in a brittle manner. However, no metallographic evidence was provided. In another study, Satoh et al. conducted laser welding of CPTi and SS316 and performed tensile tests on samples with 0 , 150 and $300 \mu \mathrm{m}$ offset to the Ti side from the Ti-SS interface; however, the strength was far lower than those of the base material [5]. The fracture surfaces were brittle. The authors presented metallographic evidence of the weld profile, energy dispersive X-ray spectroscopy (EDS) line scan of various areas, as well as electron backscattered diffraction (EBSD) and scanning electron micrographs (SEM). They suggested that the fracture occurred along the CPTi and SS interface weld pool. Based on their study, they also suggested that the upper weld pool (face surface) had a rich Ti content and the lower weld pool (closer to the root surface) had a low Ti content.

Chen et al. studied the weldability of Ti6Al4V and stainless steel 201 by offsetting the laser beam to either side of the weld line [6]. They reported better weldability and a more durable weld when the beam was offset on the stainless-steel side than on the titanium side due to the higher thermal conductivity of stainless steel compared with titanium and resulting in a narrower weldment. The interfacial structures of the joint were $\mathrm{FeAl}+\mathrm{Ti} / \mathrm{Fe}_{2} \mathrm{Ti}+\mathrm{Ti}_{5} \mathrm{Fe}_{17} \mathrm{Cr}_{5}, \mathrm{FeAl}+\mathrm{Ti} / \mathrm{FeTi}+\mathrm{Fe}_{2} \mathrm{Ti}+\mathrm{Ti}_{5} \mathrm{Fe}_{17} \mathrm{Cr}_{5}$ and $\mathrm{FeAl}+\mathrm{Ti}$. The presence of the $\alpha$-Ti at all fracture surfaces may indicate that the joint fractured along the layer that contained $\alpha-\mathrm{Ti}$ and FeTi. It was concluded that the fracture occurred between two adjacent intermetallic layers, i.e., $\mathrm{FeTi}+\alpha$ - $\mathrm{Ti}$ and $\mathrm{FeTi}+\mathrm{Fe}_{2} \mathrm{Ti}+\mathrm{Ti}_{5} \mathrm{Fe}_{17} \mathrm{Cr}_{5}$. Akbarimousavi and GohariKia investigated dissimilar welding between CPTi and AISI 316L using continuous friction welding [7]. They reported the presence of various phases and intermetallic compounds such as FeTi, $\mathrm{Fe}_{2} \mathrm{Ti}, \mathrm{Fe}_{2} \mathrm{Ti}_{4} \mathrm{O}, \mathrm{Cr}_{2} \mathrm{Ti}$ and $\alpha$-Ti at the interface, which reduced the tensile strength. They reported that hardness values increased sharply at the interface zone where the aforementioned phases were present. Ghosh and Chatterjee performed solid-state diffusion bonding of CPTi to stainless steel 304 and observed intermetallic phases such as $\sigma, \mathrm{Fe}_{2} \mathrm{Ti}_{1} \mathrm{Cr}_{2} \mathrm{Ti}$ and $\mathrm{FeTi}$ in the interface area [8,9]. The authors claimed that these phases were brittle and responsible for weakening the interface although no hardness values were provided. However, a tensile strength of around $225 \mathrm{MPa}$ (vs. CPTi $=319 \mathrm{MPa}$ and SS304 $=569 \mathrm{MPa}$ ) was achieved in this experiment. Other phases such as $\alpha$-Fe, $\beta$ - $\mathrm{Ti}$ and $\mathrm{Fe}_{2} \mathrm{Ti}_{4} \mathrm{O}$ were also present at the weld interface.

Despite the above-mentioned attempts, there is still a lack of direct metallographic evidence of phases within the weld zone, particularly from that of fusion welding. In this study, autogenous welding of CPTi and SS304 was performed using two fairly different welding techniques with different welding speeds and magnitude of heat input. Gas tungsten arc welding (GTAW) and laser beam welding (LBW) were employed to compare the effect of welding speed, power density and cooling rates on the formation of undesired intermetallic phases with the assumption that GTAW is lower in all the above-mentioned welding parameters. Clear metallographic evidence such as phases present and their chemical compositions are elaborated and correlated with their hardness, grain structure and fracture surfaces. 


\section{Experimental Procedures}

\subsection{Materials}

The materials used in the reported investigation were commercially pure titanium (CPTi) (Grade $2 \mathrm{Ti}$ ) and stainless steel 304 (SS304). The thickness of the sheet used in this investigation was $1.6 \mathrm{~mm}$. The nominal composition of the materials is given in Table 1.

Table 1. Chemical composition of commercially pure titanium (CPTi) and stainless steel 304 (SS304) (wt.\%).

\begin{tabular}{cccccccccc}
\hline Material & $\mathbf{T i}$ & $\mathbf{F e}$ & $\mathbf{H}$ & $\mathbf{N}$ & $\mathbf{O}$ & $\mathbf{C}$ & $\mathbf{C r}$ & $\mathbf{N i}$ & $\mathbf{M n}$ \\
\hline CPTi & 99 & & $<0.015$ & $<0.03$ & $<0.25$ & $<0.1$ & - & - & - \\
SS304 & - & 72 & - & - & - & - & $18-20$ & $8-10$ & $<2.0$ \\
\hline
\end{tabular}

Note: for SS304: $p<0.045 ; \mathrm{Si}<1.0 ; \mathrm{S}<0.03$.

\subsection{Welding Procedures}

Two welding techniques were employed in this study, i.e., GTAW and LBW, both with the intention of full penetration along the centre line. GTAW was performed with a direct current electrode negative (DCEN) of $50 \mathrm{~A}$, a voltage of $10 \mathrm{~V}$ coupled with argon gas shielding of $12-16 \mathrm{~L} / \mathrm{min}$ with a travelling speed of around $0.3 \mathrm{~m} / \mathrm{min}(5 \mathrm{~mm} / \mathrm{s})$. The tungsten electrode used in the experiment was a thoriated one with a diameter of $2.4 \mathrm{~mm}$ sharpened to $0.8-1 \mathrm{~mm}$ tip flat. In comparison, the laser welding was conducted with a TruDisk 16002 machine (Trumpf, Ditzingen, Germany) with a power of $3 \mathrm{~kW}$, the focus beam diameter at focal position of around $0.28 \mathrm{~mm}$, travelling speed of $6 \mathrm{~m} / \mathrm{min}$ $(100 \mathrm{~mm} / \mathrm{s})$ with argon gas shield of $30 \mathrm{~L} / \mathrm{min}$. Laser welding was performed at the Joining and Welding Research Institute (JWRI) in Osaka University. In both cases, the length of the weldments was about $100 \mathrm{~mm}$ long to allow sufficient sampling.

\subsection{Metallography}

A number of cross-sections were cut from the joint materials for metallographic examination. They were cut perpendicular to the welding line and mounted using a conductive bakelite resin. The mounted samples were ground and polished down to $0.05 \mu \mathrm{m}$ colloidal silica on polishing cloths. For backscattered electron images (BSEI) (Hitachi High Technologies, Schaumburg, IL, USA) and EDS analyses (EDAX Inc., Mahawah, NJ, USA), the samples were examined in the un-etched condition. However, for the light optical microscopy, the samples were etched with two different etchants, i.e., Kroll's and Kalling's reagents for CPTi and SS304, respectively. To improve the electron backscatter diffraction (EBSD) (EDAX Inc., Mahawah, NJ, USA) signal, an attack polish of $0.05 \mu \mathrm{m}$ colloidal silica and $30 \%$ hydrogen peroxide was used for final polishing before EBSD analysis.

\subsection{Microhardness}

Hardness tests were conducted on the polished and etched samples using a micro-Vickers (Leco AMH 55, St. Joseph, MI, USA) with a load of $300 \mathrm{~g}$ for bulk hardness measurements, and with $25 \mathrm{~g}$ load for hardness measurements of phases, layers or other small/narrow features.

\subsection{Fracture Surface Examination}

A scanning electron microscope (SEM), Hitachi SU70 (Hitachi High-Technologies Corporation, Minato-ku, Tokyo, Japan) was employed to study the fracture surfaces following ultrasonic cleaning for $10 \mathrm{~min}$ using ethanol.

\subsection{Electron Microscopy and Grain Structure}

A Hitachi 4300SE FEG scanning electron microscope was used for EBSD analysis. An EDAX Hikari camera (EDAX Inc., Mahawah, NJ, USA) and OIM software (OIMDC 6/OIM Analysis 6, 
Mahawah, NJ, USA) were used to collect patterns. Inverse pole figure (IPF) and phase maps were produced from the scans and overlaid with Image Quality (IQ) grayscale maps.

\section{Results and Discussion}

Figure 1 presents LBW and GTAW samples after welding. The LBW sample remained intact after welding. The width of the weldment was 1-2 mm (Figure 1a). For the GTAW (Figure 1b), cracking was observed on the weldment joint line about 10-20 mm behind the weld pool (GTAW torch) while the torch was still in motion, and the whole sample was completely fractured shortly after the welding process had been completed. Shanmugaran and Padmanabhan [4] reported similar results with extensive cracking on autogenous welding between CPTi and SS304, and the joint pieces broke while being removed from the welding fixture following laser welding. Chen et al. [6] observed similar results when the laser was placed at the centre, and the fracture was worse when it was offset to the titanium side. Satoh et al. [5] reported a slightly better result where the welded samples remained intact, but following the tensile test, the strengths were fairly low, i.e., between 41 and $81 \mathrm{MPa}$.

The metallographic cross-sections of both welds imaged using optical microscopy are presented in Figure 2. The weld profiles from LBW and GTAW were completely different, having a fairly narrow weld zone on the former and a fairly wide on the latter. Figure 2a shows a poorly mixed fusion zone (FZ) in LBW with a very narrow heat-affected zone (HAZ). The face surface had a width of around $1 \mathrm{~mm}$ and became narrower towards the root surface. Figure $2 \mathrm{~b}$ indicates the fusion zone on the CPTi side. The HAZ was fairly wide as indicated by the white arrows and the dashed line separating it from the fusion zone. Higher magnification optical micrographs of selected areas are presented in Figures 3 and 4. Cracks were present at the boundary between FZ and HAZ or base metal (BM) of the SS304 side. Higher magnification of the crack indicated a smooth path when it propagated along the bright area and became fairly rugged along the dark, dendritic area.
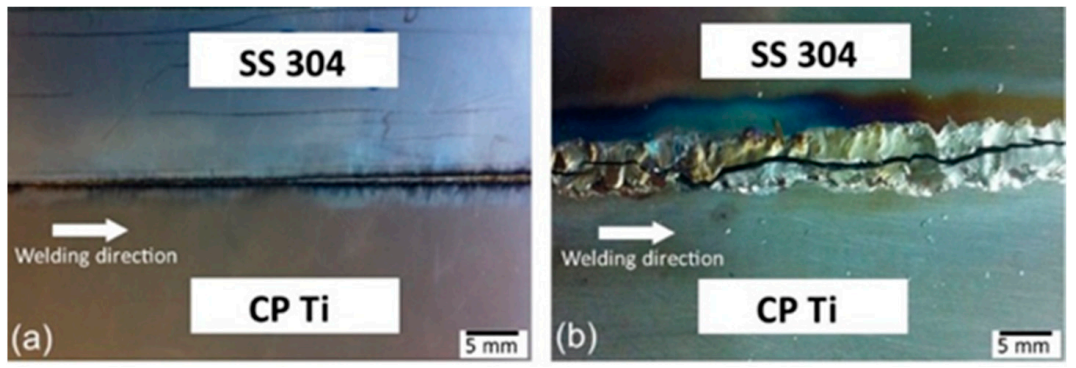

Figure 1. Optical macrographs showing commercially pure titanium (CPTi) and stainless steel 304 (SS304) interface following welding by (a) laser beam welding (LBW) and (b) gas tungsten arc welding (GTAW).
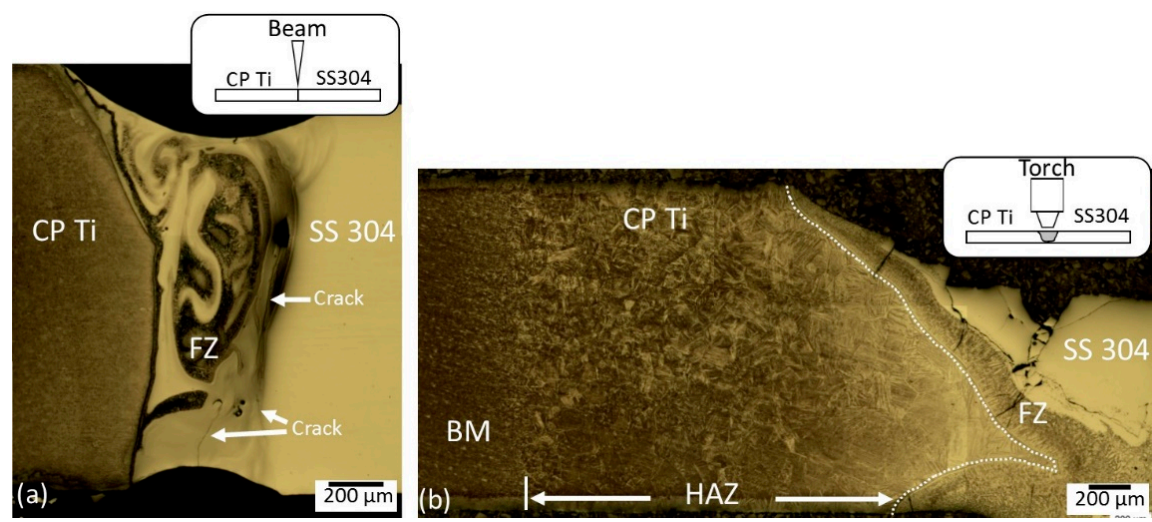

Figure 2. Low magnification optical micrographs showing weld profiles of (a) LBW and (b) GTAW. The dashed white line on $(\mathbf{b})$ has been added to illustrate the boundary between fusion and heat-affected zones. Note: insets show schematic welding process for LBW and GTAW. 
Hardness measurements from selected areas of both LBW and GTAW are given in Figures $3 b$ and $4 c$. Note the hardness of the BM of CPTi was around $300 \mathrm{HV}$ and around $210 \mathrm{HV}$ for SS304. Hardness values on the weldments varied significantly. For LBW, the hardness of the FZ reached a value of up to $1660 \mathrm{HV}$ in the bright areas (Figure 3b). Manikandan et al. [10] reported hardness values of up to $1392 \mathrm{HV}$ in the FZ following their explosive welding of titanium/stainless steel, while others reported hardness values of less than $1000 \mathrm{HV}$ in the interface [3,7]. At the small area (shown in black box) of the GTAW sample, the hardness measured at CPTi was between 520 and $545 \mathrm{HV}$ (Figure 4c). This was comparable to the hardness of the bright layer adjacent to the CPTi with a hardness of $535 \mathrm{HV}$. This value was significantly different from the Ti base metal (BM) found in the LBW sample ( 300 HV); hence, this area was the heat-affected zone. This hardness value of the Ti BM was not found in the current study of this GTAW sample (Figure 4c). It was again noted that the highest hardness in the GTAW sample was in the bright phase, i.e., up to $1420 \mathrm{HV}$ (Figure 4c).

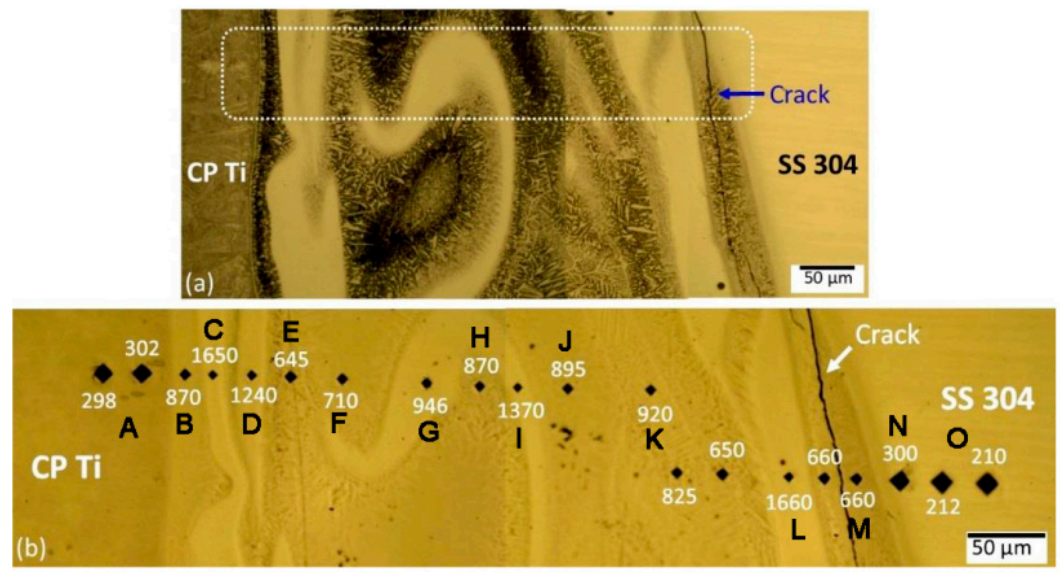

Figure 3. Optical micrographs of LBW showing (a) a distinct solidification pattern with the dashed line box indicating the area of interest for hardness measurements, chemical composition analysis and phase identification, and (b) the hardness distribution within the dashed line box area. The compositions of labels A-O are overlaid in the phase diagram (Figure 6) [11].
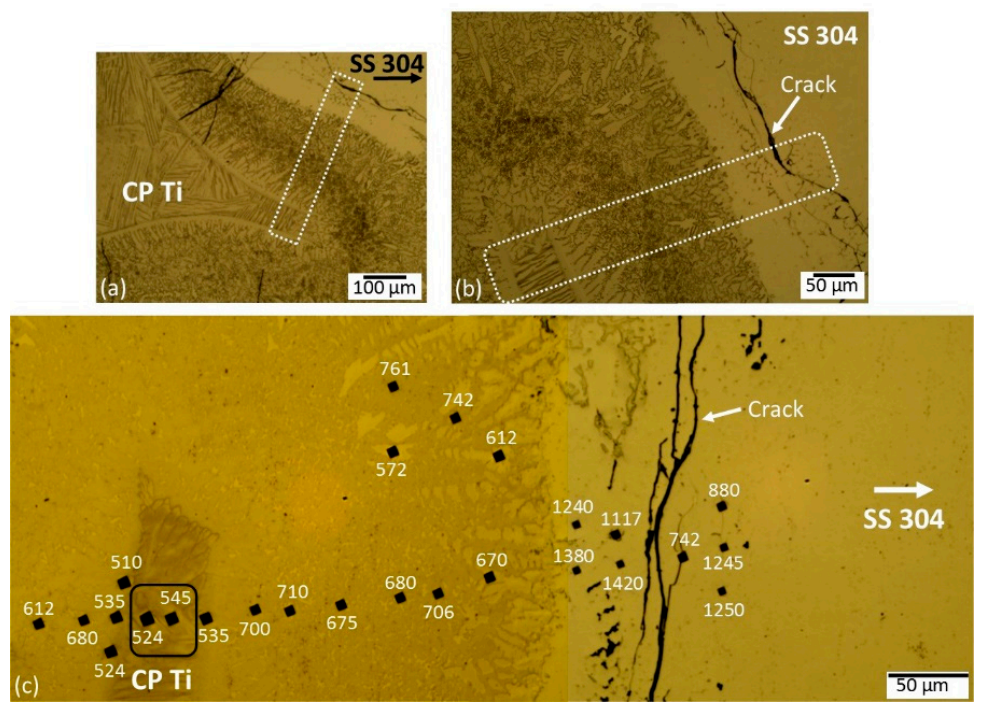

Figure 4. Optical micrographs of GTAW showing (a) low magnification and (b) higher magnification of the "weld zone" with the dashed line box indicating the area of interest for hardness measurements, chemical composition analysis and phase identification, and (c) the hardness distribution within the dashed line box area. Note that hardness values around the cracks are comparable to those adjacent to the fracture surface area, i.e., 970 to $1300 \mathrm{HV}$. 
The backscattered electron image together with the chemical compositions across the FZ of the LBW sample is presented in Figure 5a,b, respectively. In addition, the hardness values from Figure 3 are correlated with the measured chemical compositions at different locations (Table 2). Based on the isothermal ternary phase diagram of Fe-Cr-Ti at $550{ }^{\circ} \mathrm{C} \mathrm{[10],} \mathrm{the} \mathrm{possible} \mathrm{phases} \mathrm{formed} \mathrm{are}$ identified in Figure 6. The nickel concentration was not considered when identifying the phases. The intermetallic phases formed closest to the Ti BM (point B in Figure 3) were both cubic FeTi and $\mathrm{Fe}_{y}\left(\mathrm{Ti}_{1-x} \mathrm{Cr}_{x}\right)$ with space group $P m \overline{3} m$ and $\operatorname{Im} \overline{3} m$, respectively. The band of high hardness (1650 HV) was identified as hexagonal $\mathrm{P6}_{3} / m m c\left(\mathrm{Fe}_{1-x} \mathrm{Cr}_{x}\right)_{2} \mathrm{Ti}$ (Point C). In their work, Manikandan et al. reported the highest hardness values belonged to FeTi and $\mathrm{Fe}_{2} \mathrm{Ti}$ [10]. Further away from the $\mathrm{Ti} \mathrm{BM}$, the $\mathrm{Ti}$ at.\% increased creating FeTi and $\left(\mathrm{Fe}_{1-x} \mathrm{Cr}_{x}\right)_{2} \mathrm{Ti}$ with slightly lower hardness. A soft dendritic region containing 53 at.\% Ti, 8 at.\% $\mathrm{Cr}, 34$ at.\% Fe and 5 at.\% Ni (points $\mathrm{E}$ and F) was identified as a combination of three phases- $\mathrm{FeTi}, \mathrm{Fe}_{y}\left(\mathrm{Ti}_{1-x} \mathrm{Cr}_{x}\right)$ and $\left(\mathrm{Fe}_{1-x} \mathrm{Cr}_{x}\right)_{2} \mathrm{Ti}$, with a hardness of $\sim 700 \mathrm{HV}$. Another unique intermetallic phase of $\mathrm{Ti}_{5} \mathrm{Fe}_{17} \mathrm{Cr}_{7}$ (hexagonal, $P 6_{3} / \mathrm{mmm}$ ) was found at position $\mathrm{G}$ together with $\left(\mathrm{Fe}_{1-x} \mathrm{Cr}_{x}\right)_{2} \mathrm{Ti}$ when the Ti content decreased with increasing Fe, consistent with the report by Chen et al. [6]. The hardest intermetallic phase ( $>1000 \mathrm{HV})$ was determined to be $\left(\mathrm{Fe}_{1-x} \mathrm{Cr}_{x}\right)_{2} \mathrm{Ti}$, while a mixed phase of FeTi and $\mathrm{Fe}_{y}\left(\mathrm{Ti}_{1-x} \mathrm{Cr}_{x}\right)$ crystallised with a hardness of 600-900 HV. The correlation between hardness and composition for the LBW sample is presented in Figure 7, where $500<\mathrm{HV}<1000$ was the region where FeTi $+\mathrm{Fe}_{y}\left(\mathrm{Ti}_{1-x} \mathrm{Cr}_{x}\right)$ formed, while $\left(\mathrm{Fe}_{1-x} \mathrm{Cr}_{x}\right)_{2} \mathrm{Ti}$ was found for hardness $>1000 \mathrm{HV}$.

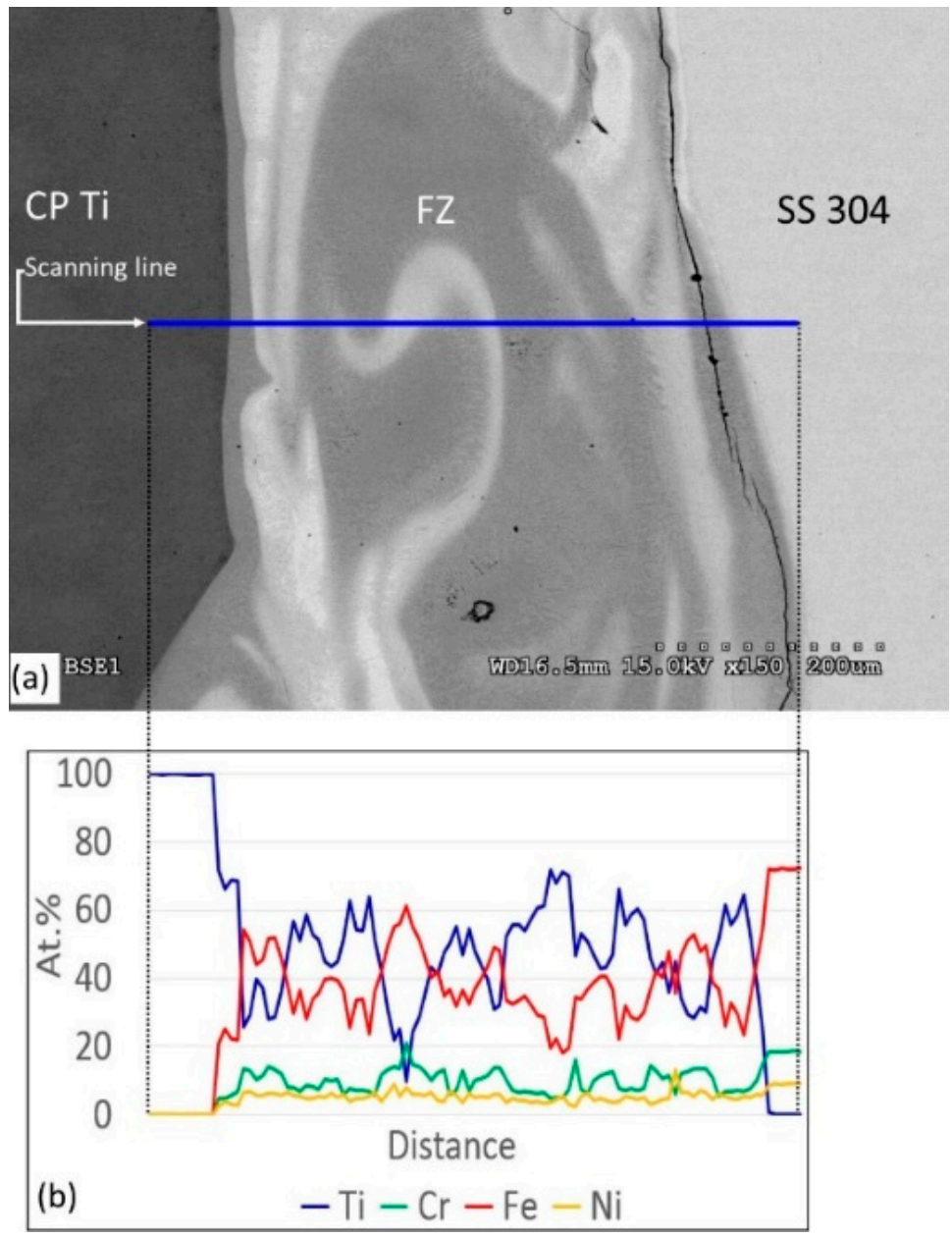

Figure 5. (a) Backscattered electron image and (b) chemical composition (at.\%) of the area along the scanned line of LBW weld profiles. 
Table 2. Correlation between hardness, chemical composition and possible phases across the LBW profile. The label A-O corresponds to Figure 3, and the corresponding chemical composition is overlaid in Figure 6 [11].

\begin{tabular}{|c|c|c|c|c|c|c|}
\hline Location & HV & Possible Phases & $\mathrm{Ti}$ & $\mathrm{Cr}$ & Fe & $\mathrm{Ni}$ \\
\hline A & $298 ; 302$ & $\alpha \mathrm{Ti}$ & 99.9 & 0.0 & 0.1 & 0.0 \\
\hline B & 870 & $\mathrm{FeTi}+\mathrm{Fe}_{y}\left(\mathrm{Ti}_{1-x} \mathrm{Cr}_{x}\right)$ & 68.8 & 5.5 & 22.6 & 3.0 \\
\hline $\mathrm{C}$ & 1650 & $\left(\mathrm{Fe}_{1-x} \mathrm{Cr}_{x}\right)_{2} \mathrm{Ti}$ & 29.4 & 13.1 & 50.8 & 6.8 \\
\hline $\mathrm{D}$ & 1240 & $\mathrm{FeTi}+\left(\mathrm{Fe}_{1-x} \mathrm{Cr}_{x}\right)_{2} \mathrm{Ti}$ & 37.5 & 11.2 & 45.2 & 6.2 \\
\hline $\mathrm{E}$ & 645 & $\mathrm{FeTi}+\mathrm{Fe}_{y}\left(\mathrm{Ti}_{1-x} \mathrm{Cr}_{x}\right)+\left(\mathrm{Fe}_{1-x} \mathrm{Cr}_{x}\right)_{2} \mathrm{Ti}$ & 52.7 & 8.2 & 33.9 & 5.2 \\
\hline $\mathrm{F}$ & 710 & $\mathrm{FeTi}+\mathrm{Fe}_{y}\left(\mathrm{Ti}_{1-x} \mathrm{Cr}_{x}\right)+\left(\mathrm{Fe}_{1-x} \mathrm{Cr}_{x}\right)_{2} \mathrm{Ti}$ & 54.8 & 7.8 & 32.5 & 4.9 \\
\hline G & 946 & $\left(\mathrm{Fe}_{1-x} \mathrm{Cr}_{x}\right)_{2} \mathrm{Ti}+\mathrm{Ti}_{5} \mathrm{Fe}_{17} \mathrm{Cr}_{7}$ & 24.1 & 15.0 & 54.2 & 6.7 \\
\hline $\mathrm{H}$ & 870 & $\mathrm{FeTi}+\mathrm{Fe}_{y}\left(\mathrm{Ti}_{1-x} \mathrm{Cr}_{x}\right)+\left(\mathrm{Fe}_{1-x} \mathrm{Cr}_{x}\right)_{2} \mathrm{Ti}$ & 50.4 & 9.4 & 34.9 & 5.3 \\
\hline I & 1370 & $\left(\mathrm{Fe}_{1-x} \mathrm{Cr}_{x}\right)_{2} \mathrm{Ti}$ & 31.6 & 13.8 & 48.6 & 6.0 \\
\hline $\mathrm{J}$ & 895 & $\mathrm{FeTi}+\mathrm{Fe}_{y}\left(\mathrm{Ti}_{1-x} \mathrm{Cr}_{x}\right)+\left(\mathrm{Fe}_{1-x} \mathrm{Cr}_{x}\right)_{2} \mathrm{Ti}$ & 57.9 & 6.6 & 31.7 & 3.9 \\
\hline K & 920 & $\mathrm{FeTi}+\mathrm{Fe}_{y}\left(\mathrm{Ti}_{1-x} \mathrm{Cr}_{x}\right)+\left(\mathrm{Fe}_{1-x} \mathrm{Cr}_{x}\right)_{2} \mathrm{Ti}$ & 58.0 & 7.4 & 29.6 & 5.0 \\
\hline $\mathrm{L}$ & 1660 & $\mathrm{FeTi}+\left(\mathrm{Fe}_{1-x} \mathrm{Cr}_{x}\right)_{2} \mathrm{Ti}$ & 33.5 & 11.9 & 47.4 & 7.2 \\
\hline M & 660 & $\mathrm{FeTi}+\mathrm{Fe}_{y}\left(\mathrm{Ti}_{1-x} \mathrm{Cr}_{x}\right)+\left(\mathrm{Fe}_{1-x} \mathrm{Cr}_{x}\right)_{2} \mathrm{Ti}$ & 58.6 & 7.1 & 29.2 & 5.1 \\
\hline $\mathrm{N}$ & 300 & $\mathrm{SS}+\mathrm{FeTi}$ & 32.1 & 12.4 & 49.6 & 5.9 \\
\hline $\mathrm{O}$ & $212 ; 210$ & SS & 0.1 & 18.7 & 72.1 & 9.2 \\
\hline
\end{tabular}

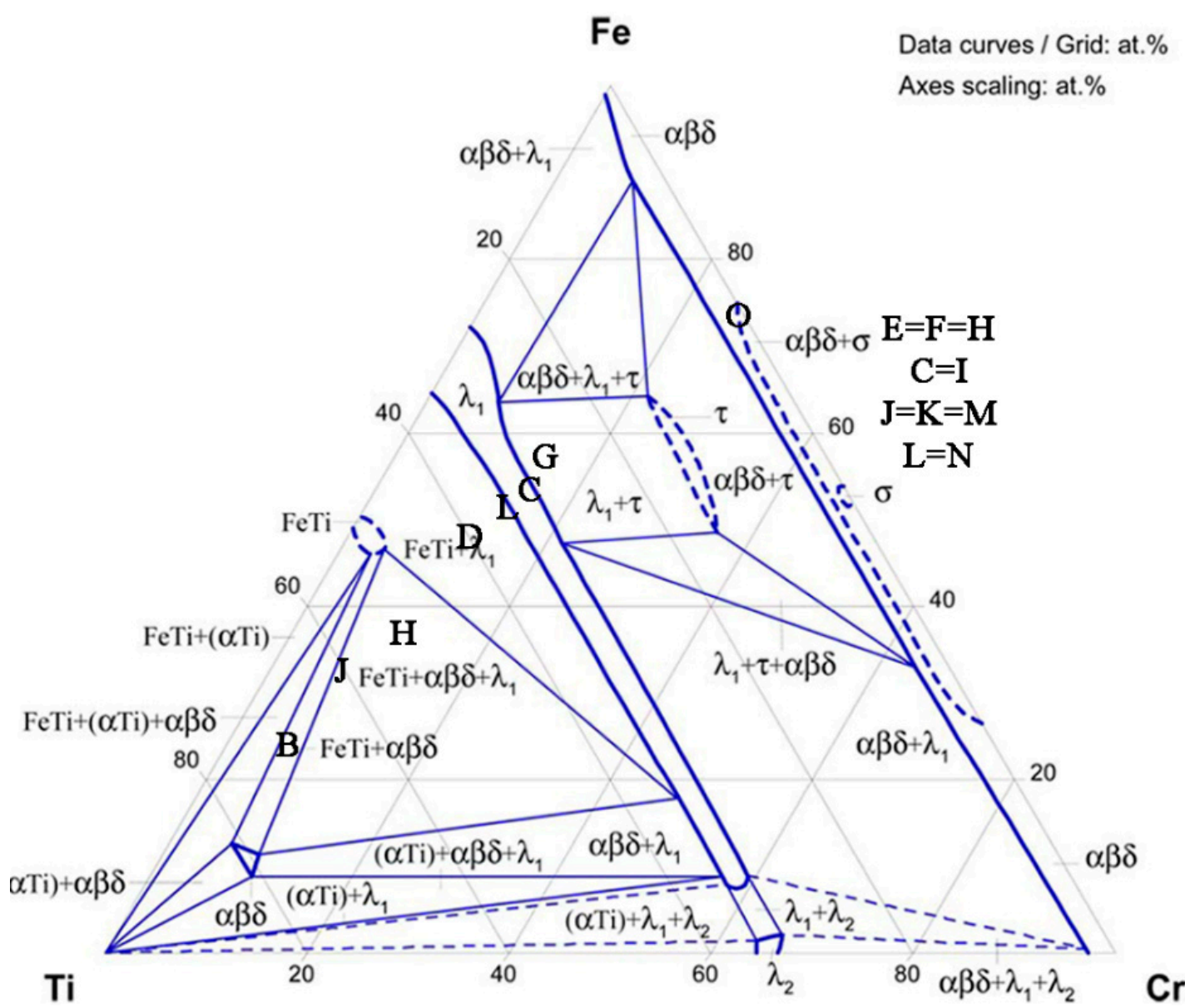

Figure 6. Isothermal $\left(550^{\circ} \mathrm{C}\right)$ ternary phase diagram of Fe-Cr-Ti adapted from [11] where labels B-O correspond to the positions in Figure 3. 


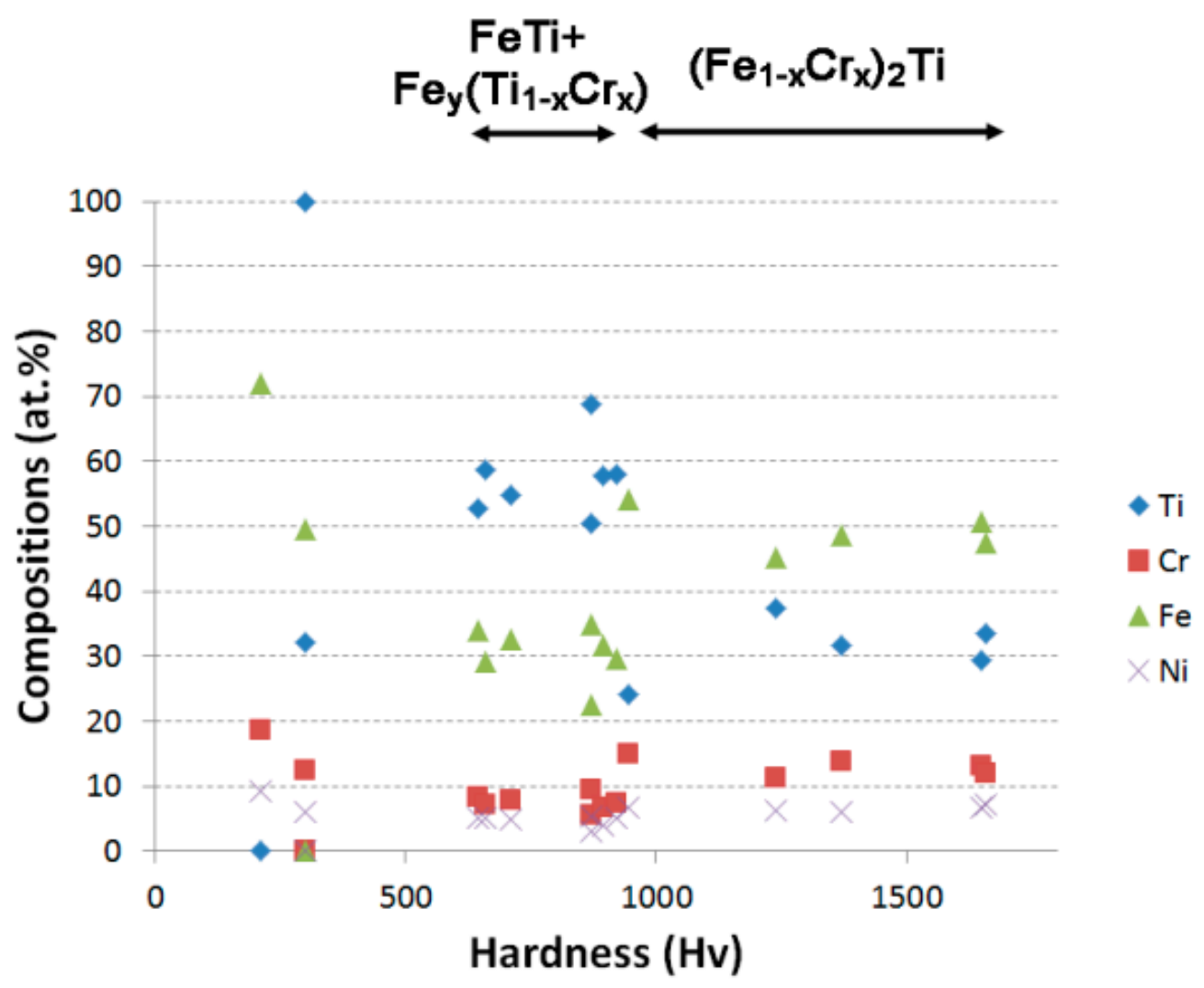

Figure 7. Variation of hardness with composition for the LBW sample.

The high hardness of the bright areas (1200-1660 HV) suggests they are the most brittle areas of the weld zone. Despite the presumed brittleness of the bright phase, cracking (or fracturing) took place between this hard phase and the softer SS304 side.

To identify the phases present in the weld zone and their corresponding grain orientations, electron backscattered diffraction (EBSD) was performed. EBSD analysis considered only binary $\mathrm{Fe}$-Ti compounds assuming $\mathrm{Cr}$ and $\mathrm{Ni}$ are solid substitutions for either Fe or Ti. As described earlier, FeTi and $\mathrm{Fe}_{y}\left(\mathrm{Ti}_{1-x} \mathrm{Cr}_{x}\right)$ crystallised in the same cubic crystal system, while $\mathrm{Fe}_{2} \mathrm{Ti}_{1},\left(\mathrm{Fe}_{1-x} \mathrm{Cr}_{x}\right)_{2} \mathrm{Ti}$ and $\mathrm{Ti}_{5} \mathrm{Fe}_{17} \mathrm{Cr}_{7}$ were hexagonal. In addition, only a limited number of references have reported ternary $\mathrm{Fe}-\mathrm{Cr}$-Ti compounds. Crystallographic information taken from Yan et al. [12] (Inorganic Crystal Structure Database (ICSD) code 155674) and Thompson et al. [13] (ICSD code 633925) were used to index $P 6_{3} / m m c \mathrm{Fe}_{2} \mathrm{Ti}$ and $P m \overline{3} m \mathrm{FeTi}$, respectively. On the CPTi side, it can be observed that a FeTi phase formed along the interface of both LBW and GTAW weldments while on the SS304 side, the boundary consisted of mixed phases. The FeTi layer adjacent to CPTi on LBW was thinner and the grains much smaller than those observed on GTAW (Figures 8 and 9). More elongated grains were generally observed for the $\mathrm{Fe}_{2} \mathrm{Ti}$ phase.

Upon etching, a range of dendrite sizes was observed. In the FZ of both welds (Figures 10 and 11), two clear areas were evident, i.e., one showing a high density of dendritic phase, and a plain/smooth area. The grain structure in these two types of welds showed some differences. Large grains were observed in the CPTi region of the GTAW weld, likely due to the high heat input. At the boundary interface, the FeTi phase on the LBW sample was fairly narrow and had a smaller average grain size, but on GTAW was about ten times thicker and had larger grains. 


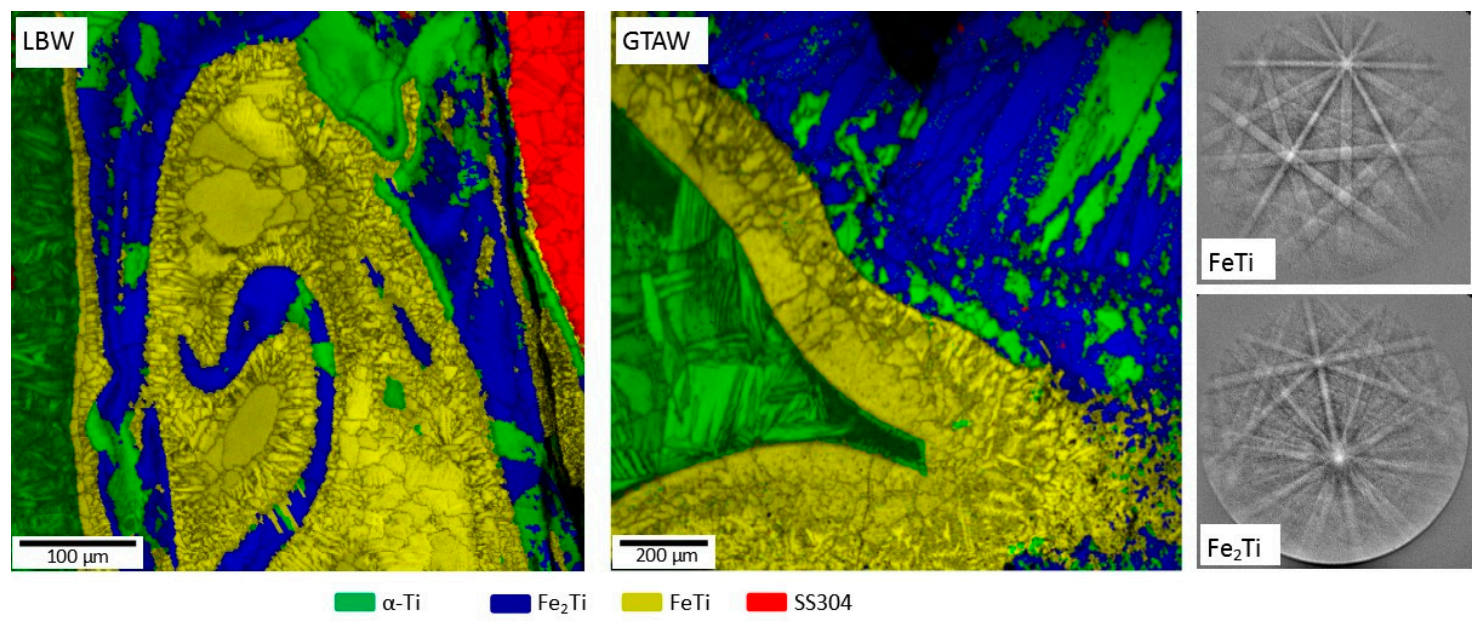

Figure 8. Electron backscattered diffraction (EBSD) phase map with image quality (IQ) overlay showing intermetallics present in the CPTi/SS304 weld zone. Scan step size is $1.5 \mu \mathrm{m}$. The EBSD patterns of FeTi and $\mathrm{Fe}_{2} \mathrm{Ti}$ are also shown.
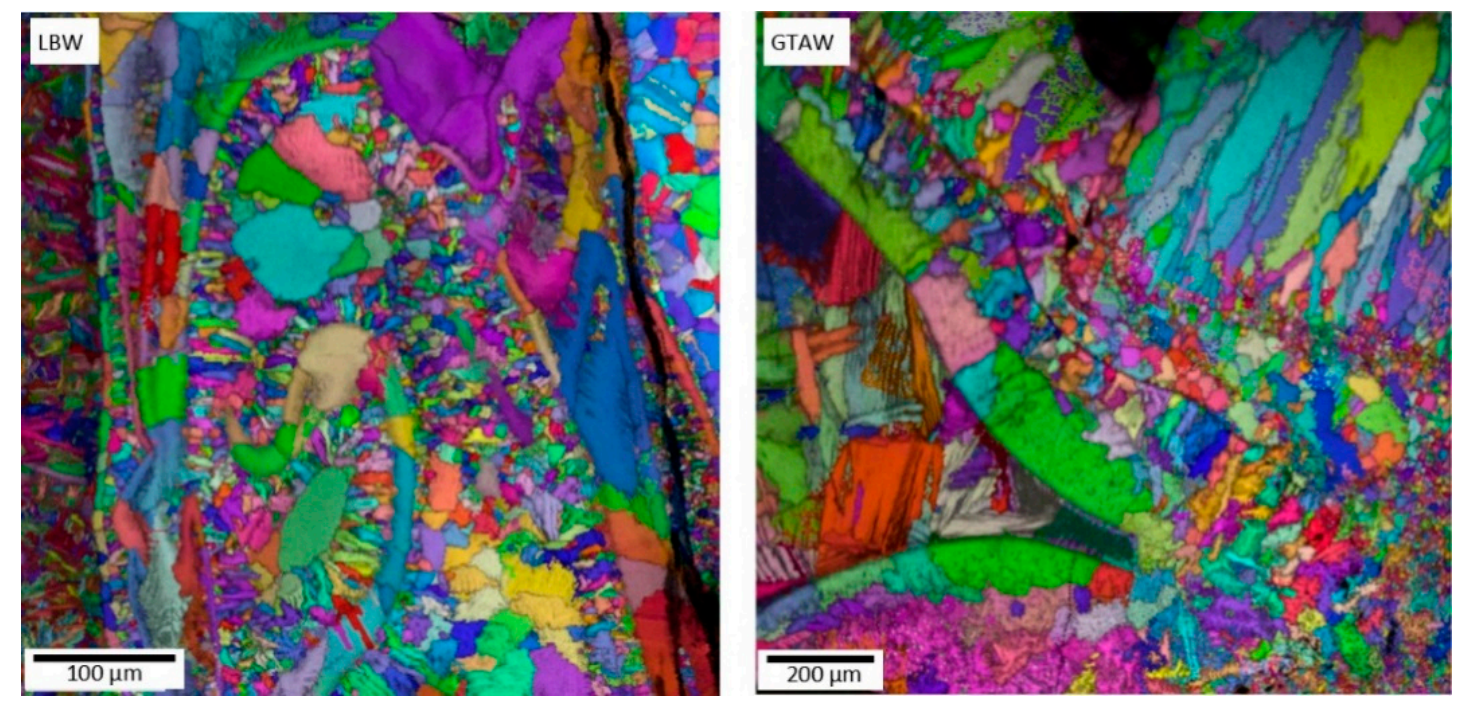

Figure 9. Corresponding EBSD inverse pole figure (IPF) maps with IQ overlay from Figure 8.

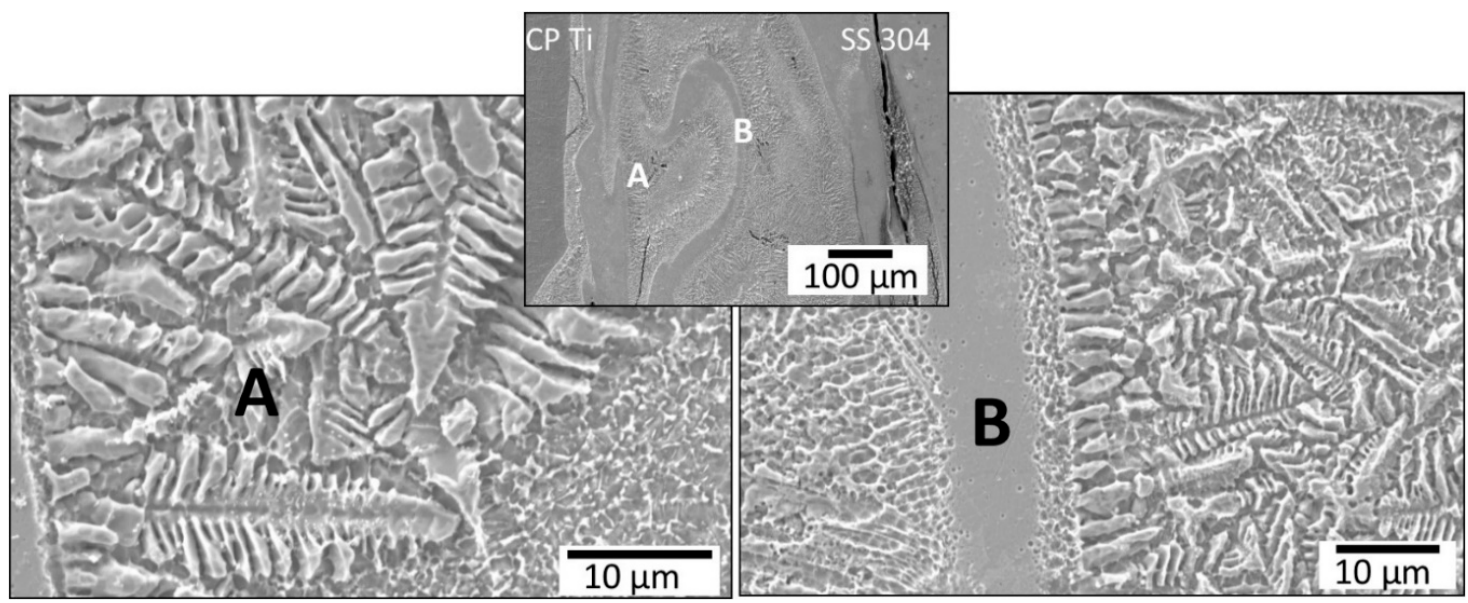

Figure 10. SEM image of LBW showing the fusion zone (FZ) and cracking on the SS304 side where (A) showing extensive mainly FeTi dendrite phase, and (B) showing a fairly smooth $\left(\mathrm{Fe}_{1-x} \mathrm{Cr}_{x}\right)_{2} \mathrm{Ti}$ patch surrounded by mainly FeTi dendrites. The inset shows the general LBW profile. 

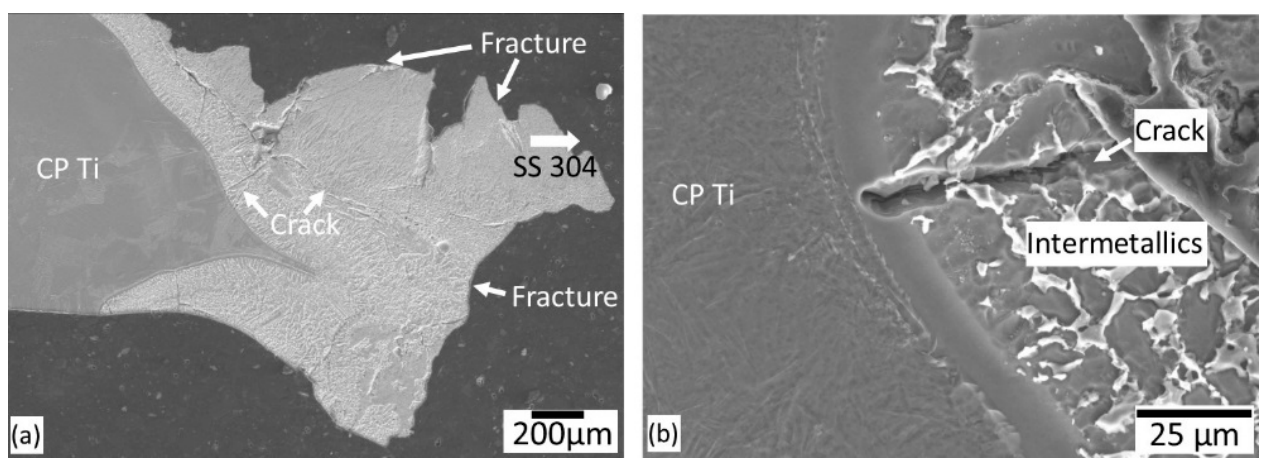

Figure 11. SEM images of GTAW showing (a) the fusion zone and fracture locations on the SS304 side, and $(\mathbf{b})$ intermetallic compounds including a layer adjacent to the CPTi.

For GTAW welds, the fracture occurred mainly along the centreline of the weld. SEM images showing fracture surfaces are given in Figure 12. It can be seen that the fracture surface was almost entirely cleavage, indicating a brittle weld joint. A similar observation was reported by Satoh et al. [5] as well as by Chen et al. [6] where brittle characteristics were observed along with river patterns. As mentioned earlier, cracking was taking place during welding, and fracturing occurred immediately after welding. For LBW, the welded pieces were intact after welding and survived throughout wire cutting for the preparation of the dog-bone samples, but completely separated prior to tensile testing. Therefore, tensile testing was not performed. However, fracture surfaces were available for examination. Fractures took place at the weld zone on the SS304 side (also reported by Satoh et al. [5]). Figure 3a also shows cracking on the weld zone at the SS304 side. Upon examination of the fracture surfaces, one can see a mixture of fracture mechanisms from cleavage to fairly rugged features. One of the reasons as to why cracking and or fracturing took place in the SS304 side may be related to the thermal properties. Table 3 provides the thermal properties of CPTi and SS304 including thermal conductivity and the thermal expansion coefficient. The thermal expansion coefficient-which relates the change in volume due to a change in temperature-of stainless steel is twice as high as titanium, suggesting that thermal stress is more easily built up on the SS304 side.

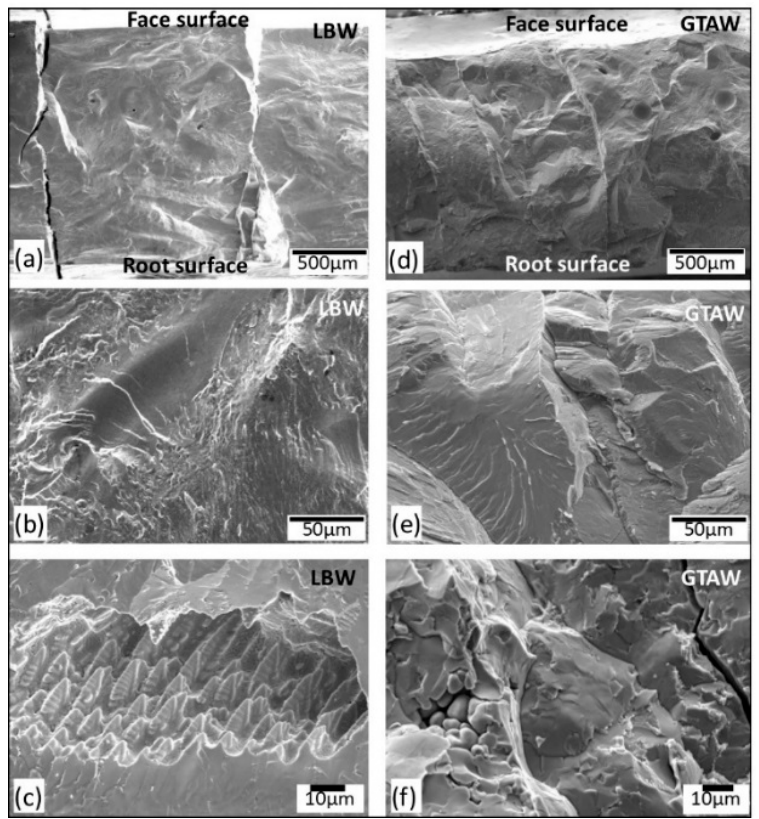

Figure 12. SEM images showing the fracture surface of $(\mathbf{a}-\mathbf{c})$ LBW and $(\mathbf{d}-\mathbf{f})$ GTAW samples. Gas pores are visible on (d); an extensive cleavage fracture is shown in $(\mathbf{e}, \mathbf{f})$; porosities due to incomplete solidification are evident in $(\mathbf{c}, \mathbf{f})$. 
Table 3. Thermal properties of CPTi and SS304 [14,15].

\begin{tabular}{ccc}
\hline Properties & CPTi & SS304 \\
\hline Density $\left(\mathrm{g} / \mathrm{cm}^{3}\right)$ & 4.5 & 7.8 \\
Melting point $\left({ }^{\circ} \mathrm{C}\right)$ & 1665 & $1400-1455$ \\
Thermal conductivity $\left(\mathrm{W} \mathrm{m}{ }^{-1} \mathrm{k}^{-1}\right)$ & $16-22$ & $14-19$ \\
Thermal expansion coefficient $\left(\mathrm{m} / \mathrm{m} /{ }^{\circ} \mathrm{C}\right)$ & $9 \times 10^{-6}$ & $16 \times 10^{-6}$ \\
Thermal diffusivity $\left(\mathrm{m}^{2} / \mathrm{s}\right)$ & $6.9 \times 10^{-6}$ & $4.2 \times 10^{-6}$ \\
Specific heat capacity $\left(\mathrm{J} / \mathrm{g}^{\circ} \mathrm{C}\right)$ & $0.523-0.69$ & 0.500 \\
\hline
\end{tabular}

\section{Conclusions}

Based on the experimental results, metallographic observations, phase identifications and fractography examination, the following points are concluded:

1. Neither LBW nor GTAW was able to produce a sound weld joint of CPTi and SS304. As a joint was nearly made using LBW, this will be the focus for future investigations. The samples from GTAW separated immediately after welding was completed.

2. Fractures were observed mainly on the SS304 side and are hypothesised to be due to the higher thermal expansion coefficient of SS304 compared to CPTi.

3. The fracture surface was predominantly covered by brittle fracture features, e.g., cleavage and fairly flat.

4. Hardness was found to have increased significantly from $210-300 \mathrm{HV}$ in the base metal to $1660 \mathrm{HV}$ and $1420 \mathrm{HV}$ in the weld zones in LBW and GTAW, respectively.

5. The hardest phase was identified to be $\left(\mathrm{Fe}_{1-x} \mathrm{Cr}_{x}\right)_{2} \mathrm{Ti}$ with hardness values up to $1660 \mathrm{HV}$ observed.

Author Contributions: T.P. initiated the project, designed the experiments, and prepared the original draft; M.M. performed welding; M.A. conducted metallography and scanning electron microscopy; S.S.P. conducted phase identification and revised the paper; M.K. performed EBSD and edited the paper; W.Z.M. oversaw the entire project and provided direction; O.K. initiated and conceived the project with T.P.

Funding: This research received no external funding.

Acknowledgments: One of the authors (T.P.) would like thank Lehigh University for an appointment as a Loewy Visiting Professor financed through the endowment from the Loewy Family Foundation. The authors also thank Manabu Tanaka of JWRI, Osaka University for the use of their laser welding facilities.

Conflicts of Interest: The authors declare no conflict of interest.

\section{References}

1. American Welding Society. Welding Handbook, 7th ed.; American Welding Society: Miami, FL, USA, 1998.

2. Tomashchuk, I.; Sallamand, P. Metallurgical Strategies for the Joining of Titanium Alloys with Steels. Adv. Eng. Mater. 2018, 20, 1700764. [CrossRef]

3. Tomashchuk, I.; Sallamand, P.; Andrzejewski, H.; Grevey, D. The formation of intermetallics in dissimilar Ti6Al4V/copper/AISI 316 L electron beam and Nd:YAG laser joints. Intermetallics 2011, 19, 1466-1473. [CrossRef]

4. Shanmugarajan, B.; Padmanabham, G. Fusion welding studies using laser on Ti-SS dissimilar combination. Opt. Lasers Eng. 2012, 50, 1621-1627. [CrossRef]

5. Satoh, G.; Yao, Y.L.; Qiu, C. Strength and microstructure of laser fusion-welded Ti-SS dissimilar material pair. Int. J. Adv. Manuf. Technol. 2013, 66, 469-479. [CrossRef]

6. Chen, S.; Zhang, M.; Huang, J.; Cui, C.; Zhang, H.; Zhao, X. Microstructures and mechanical property of laser butt welding of titanium alloy to stainless steel. Mater. Des. 2014, 53, 504-511. [CrossRef]

7. Akbarimousavi, S.A.A.; GohariKia, M. Investigations on the mechanical properties and microstructure of dissimilar cp-titanium and AISI 316L austenitic stainless steel continuous friction welds. Mater. Des. 2011, 32, 3066-3075. [CrossRef] 
8. Ghosh, M.; Chatterjee, S. Characterization of transition joints of commercially pure titanium to 304 stainless steel. Mater. Charact. 2002, 48, 393-399. [CrossRef]

9. Ghosh, M.; Chatterjee, S. Effect of interface microstructure on the bond strength of the diffusion welded joints between titanium and stainless steel. Mater. Charact. 2005, 54, 327-337. [CrossRef]

10. Manikandan, P.; Hokamoto, K.; Deribas, A.A.; Raghukandan, K.; Tomoshige, R. Explosive Welding of Titanium/Stainless Steel by Controlling Energetic Conditions. Mater. Trans. 2006, 47, 2049-2055. [CrossRef]

11. Ivanchenko, V.; Pryadko, T. Chromium-Iron-Titanium; Springer-Verlag: Berlin, Germany, 2008.

12. Yan, X.; Chen, X.-Q.; Grytsiv, A.; Witusiewicz, V.T.; Rogl, P.; Podloucky, R.; Pomjakushin, V.; Giester, G. Site preference, thermodynamic, and magnetic properties of the ternary Laves phase $\mathrm{Ti}\left(\mathrm{Fe}_{1-x} \mathrm{Al}_{x}\right)_{2}$ with the crystal structure of the $\mathrm{MgZn}_{2}$-type. Z. Metallk. 2006, 97, 450-460. [CrossRef]

13. Thompson, P.; Reilly, J.J.; Hastings, J.M. The application of the Rietveld method to a highly strained material with microtwins: TiFeD 1.9. J. Appl. Crystallogr. 1989, 22, 256-260. [CrossRef]

14. Boyer, R.; Welsch, G.; Collings, E.W. Materials Properties Handbook: Titanium Alloys; ASM International: Materials Park, OH, USA, 1994.

15. Ashby, M.F. CES EduPack; Granta Design: Cambridge, UK, 2017.

(C) 2018 by the authors. Licensee MDPI, Basel, Switzerland. This article is an open access article distributed under the terms and conditions of the Creative Commons Attribution (CC BY) license (http://creativecommons.org/licenses/by/4.0/). 